\title{
Bone Marrow Metastasis of Malignant Melanoma
}

\author{
Mitsuyo Uesawa ${ }^{1}$, Kazuya Sato ${ }^{1}$, Katsutoshi Ozaki ${ }^{1}$, Tadashi Nagai ${ }^{1}$, \\ Kazuo Muroi ${ }^{1,2}$ and Keiya Ozawa ${ }^{1,2}$
}

(DOI: 10.2169/internalmedicine.45.1616)

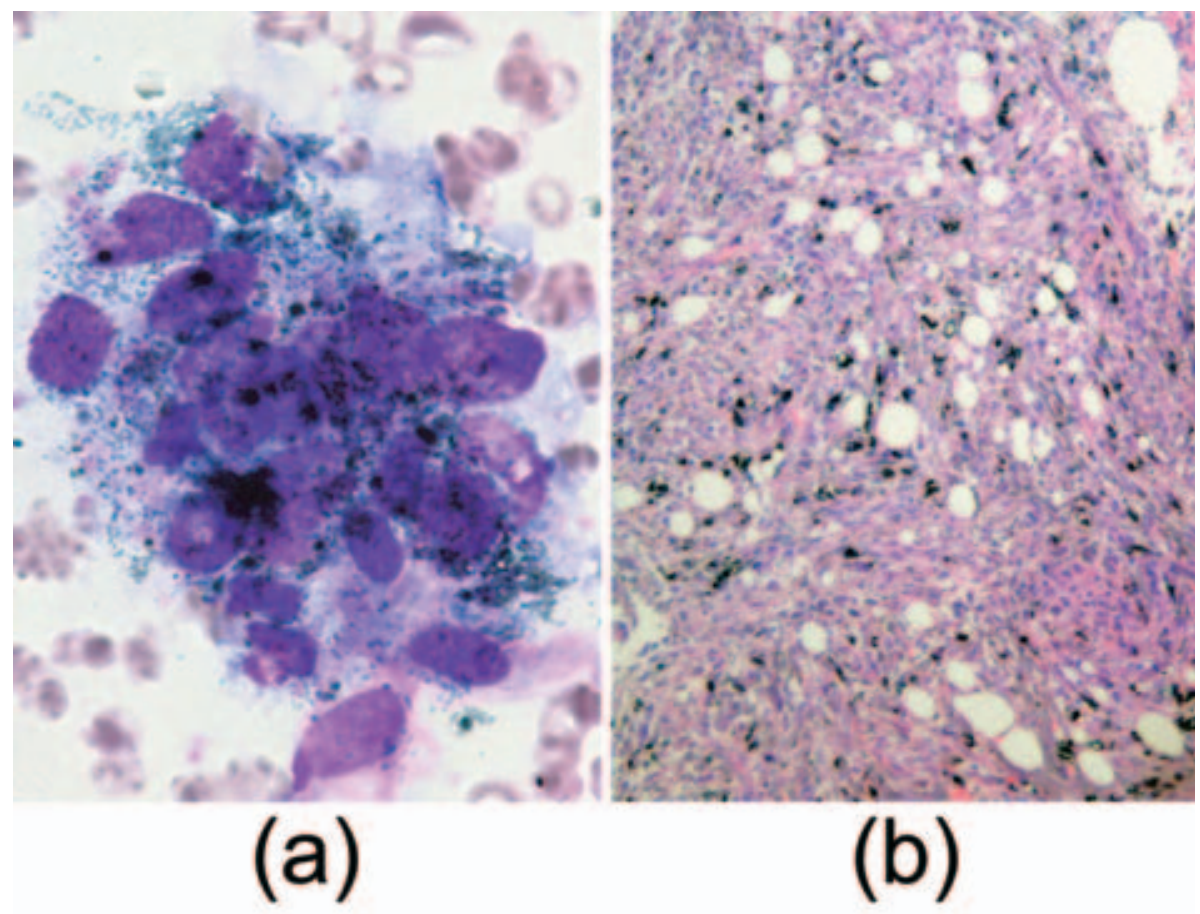

Figure 1. Bone marrow was infiltrated with tumor cells including characteristic melanin pigments (a: aspirate, b: biopsy).

A 67-year-old woman was admitted to our hospital with a 3-month history of lower back pain. One year earlier, the patient was diagnosed with malignant melanoma of the right maxillary bone and underwent an operation followed by adjuvant chemotherapy. A bone marrow aspirate revealed that the marrow was infiltrated by tumors composed of nests of poorly differentiated cells. These tumor cells were large and round shaped, and the cellular outlines within clumps of tumor cells were indistinct. Although these findings were not specific for any group of metastatic tumors, the cytoplasm of tumor cells was filled with numerous granules of melanin (Fig. 1). Thus, a diagnosis of malignant melanoma with bone marrow involvement was made. The primary site of metastatic tumors in bone marrow is difficult to determine by morphological examinations, including immunostaining. However, melanin pigments in cytoplasm are characteristic and definitive findings in malignant melanoma.

(C) 2006 The Japanese Society of Internal Medicine

http://www.naika.or.jp/imindex.html

\footnotetext{
${ }^{1}$ Division of Hematology, Jichi Medical University, Tochigi and ${ }^{2}$ Division of Transplantation and Transfusion ${ }^{3}$, Jichi Medical University, Tochigi Received for publication October 20, 2005; Accepted for publication January 11, 2006

Correspondence to Kazuya Sato, Division of Hematology, Jichi Medical University, 3311-1 Yakushiji, Simotsuke-shi, Tochigi 329-0498
} 